\title{
DETERMINATION OF NEEDED FACTS CONTROLLERS THAT INCREASE ASSET UTILIZATION OF POWER SYSTEMS
}

\author{
L.A.S. Pilotto \\ Member \\ W.W. Ping A.R. Carvalho \\ Non-Member Non-Member
CEPEL - Centro de Pesquisas de Energia Elétrica
Caixa Postal 2754 20001-970
Rio de Janeiro, Brazil

\author{
A. Wey \\ Member \\ Promon Engenharia \\ Praia do Flamengo 154 \\ $22207-900$ \\ Rio de Janeiro, Brazil
}

W.F. Long F.L. Alvarado
Fellow Fellow
C.L. DeMarco
Member
University of Wisconsin
432 North Lake Street
WI 53706-1498
Madison, USA

\begin{abstract}
The paper presents an approach for identifying the most effective Flexible AC Transmission System (FACTS) Controllers, locations, types and ratings that increase asset utilization of power systems. The approach is a combined static/dynamic procedure based on the use of a continuation power flow, an optimal power flow and an eigenvalue analysis. The application of this approach on a representative studied transmission system has resulted in an increase of the maximum stable loadability limit by $6.7 \%$. The paper finally shows that the proposed approach is helpful in coordinating the functionality of FACTS Controllers to enhance power system dynamics.
\end{abstract}

Keywords: FACTS Controllers, HVdc Transmission, Voltage Collapse, Electromechanical Stability

\section{INTRODUCTION}

Flexible AC Transmission System is a concept promoting the use of power electronic based and other static controllers to enhance controllability and increase power transfer capability. The basic idea behind the FACTS concept is to enable the transmission systems to become active elements, playing active roles in increasing the flexibility of power transfer requirements and in securing stability of the dynamics of integrated power systems. Therefore, FACTS Controllers should be designed with dynamic characteristics that effectively enhance the dynamic performance of the associated power system [1].

Power System engineers are currently facing challenges to increase the power transfer capability of existing transmission systems. FACTS offers an economical solution to accommodate that need while maintaining sufficient steady-state and transient stability margins.

A multi-FACTS configuration results when more than one FACTS Controller are located within the same electrical region. Such a situation will be a natural consequence of the growing need for using FACTS technology. Relevant questions relating to multiFACTS configurations are currently being analyzed in the scope of an EPRI Research Project [2]. The main thrust of this project is to present a general insight into the operation of multi-FACTS transmission configurations through developing analysis tools and control concepts for a proper coordination between FACTS Controllers. Power system studies are being performed using several digital tools. These tools are used in a complementary

96 WM 090-1 PWRD A paper recommended and approved by the IEEE Transmission and Distribution Committee of the IEEE Power Engineering Society for presentation at the 1996 IEEE/PES Winter Meeting, January 2125, 1996, Baltimore, MD. Manuscript submitted July 24, 1995; made available for printing December 15, 1995. basis to investigate both low and high frequency interaction phenomena. An overview of the project is presented in reference [3].

The main purpose of this paper is to present a static/dynamic approach for allocation of FACTS Controllers. The proposed approach is based on the combined use of a continuation power flow, an optimal power flow and an eigenvalue analysis. The algorithm allocates shunt connected controllers (Static VAr Compensators - SVC) to solve voltage collapse problems that may occur during major faults or due to load level increases. Series connected controllers (Thyristor Controlled Series Capacitors : TCSC) are allocated to guarantee the maximum transient synchronizing torque between electrical areas during severe faults. The static/dynamic procedure was checked by a detailed transient stability study. Several major faults were investigated showing that the location and ratings allocated for each FACTS Controller were adequate. The paper finally shows that the proposed method successfully coordinates the combined operation of SVCs and TCSCs to solve a simultaneous voltage collapse and lack of synchronizing torque problem after a severe HVdc bipole blocking.

\section{THE STUDIED TRANSMISSION SYSTEM}

The studied transmission system is shown in Figure 1: It is composed of 131 buses, 29 generators and 2 HVdc links. The system has a multi-infeed HVdc configuration with two inverters electrically adjacent while two rectifiers are remotely located and connected through a high impedance ac network [4]. Both of the $\mathrm{dc}$ links have parallel ac transmissions. Typical line, machine and regulator parameters were adopted and the controllers were tuned to guarantee a stable base case. The basic power-flow interchange for this network is presented in Figure 2. It also depicts the electrical area division adopted for this study.

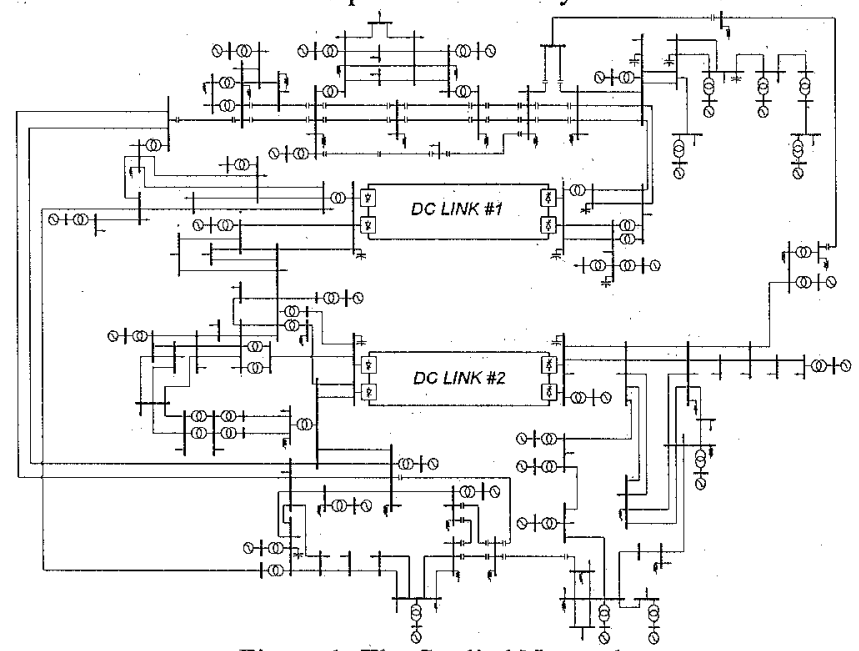

Figure 1: The Studied Network 


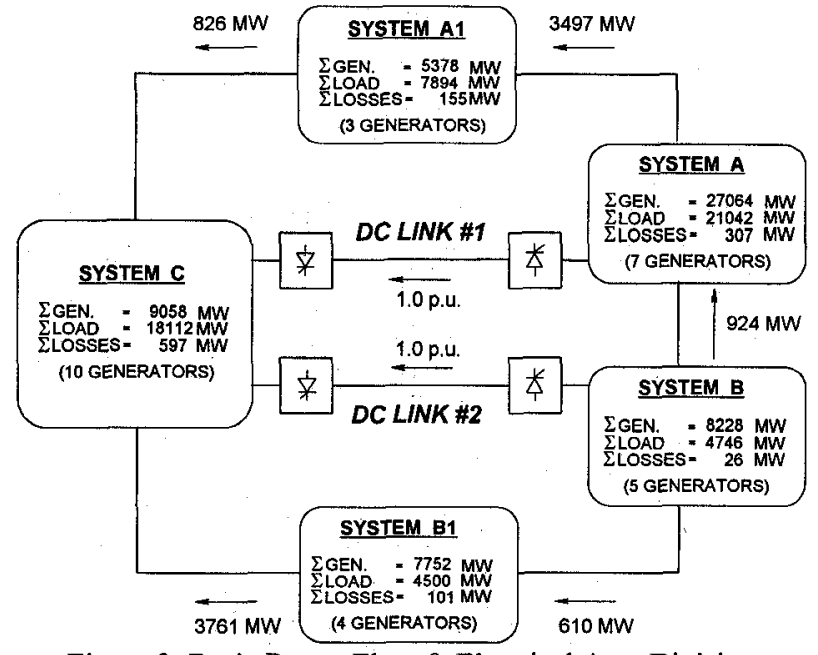

Figure 2: Basic Power Flow \& Electrical Area Division for the Studied System

\section{STATIC I DYNAMIC APPROACH FOR FACTS ALLOCATION}

The proposed method for static/dynamic allocation of FACTS Controllers is based on the combined use of a continuation power flow, an optimal power flow and an eigenvalue program. Shunt FACTS Controllers are allocated aiming at solving possible voltage collapse situations that may occur during major faults or an increase of the load level of the system. Series FACTS Controllers are allocated to guarantee the maximum transient synchronizing torque between electrical areas in the event of a major tie-line loss or HVdc blocking.

For the initial operating conditions of the system depicted in Figure 1, the total generation, load and loss levels are shown in Table 1. Figure 3 shows the voltage profile or $V \times P$ nose curves for two critical buses of the system, considering the reactive limits at the generating stations. Loads are represented as constant active and reactive powers since this is the most pessimistic scenario. The intent here is to find the PoC (Point of Collapse) of the system. The $\mathrm{PoC}$ is a measure of how far beyond the base case could the load be increased; as a percentage of base system load. Note that the \% increments necessary to reach the PoC level are $\%$ increments above a base case load level of $100 \%$. This permissible load increase beyond the base case is represented by the Loading Factor $\eta_{0}$. The parameter $\eta$ would be assumed to represent active and reactive power changes at all load buses. This is achieved by defining participation factors at the load buses that define a direction to move in parameter space [5].

In this specific case all loads are increased proportionally and this power increment is proportionally distributed among all generating stations. These nose curves correspond to bifurcation diagrams for the dynamic system model. Points above the tip of the curve, i.e., PoC or saddle-node bifurcation points, correspond to stable equilibrium points, whereas points below the tip correspond to unstable equilibria. The base case Point of Collapse analysis shows that the system is operating at an extremely loaded condition, with a maximum PoC of $2.05 \%$.

The optimal power-flow program (OPF) was initially used for optimizing the base case power flow. In this specific case, the generating station voltage levels were adjusted to minimize reactive losses. The optimized load-flow summary is presented in Table 2. It can be seen that the optimization procedure has resulted in a decrease of approximately 2,000 MVAr of reactive losses.
Table 1: Base Case Load-Flow Summary

\begin{tabular}{|c|c|c|}
\cline { 2 - 3 } \multicolumn{1}{c|}{} & MW & MVAr \\
\hline Generation & $57,475.25$ & $15,542.55$ \\
\hline Load & $56,727.40$ & $15,191.70$ \\
\hline \hline Losses & 747.84 & $4,192.80$ \\
\hline
\end{tabular}

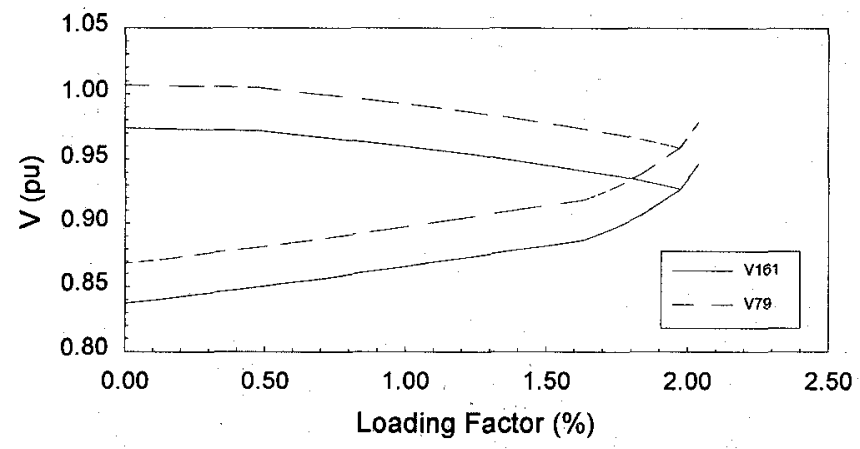

Figure 3: Point of Collapse Analysis for the Base Case

The new $V \times P$ curves obtained after the preliminary optimization using the OPF program are shown in Figure 4. The new $\mathrm{PoC}$ in this case is $\mathbf{3 . 8 7} \%$.

In sequence, an eigenvalue program [6] was used for calculating the voltage related eigenvalues of the system, around the maximum loadability point previously calculated -$\mathrm{PoC}=\mathbf{3 . 8 7} \%$. Figure 5 shows the most critical voltage associated eigenvalues of the system. There is a critical eigenvalue $\lambda=-0.1058$ indicating a voltage collapse problem in the network. The other eigenvalues are distant from the origin in the s-plane and cause no voltage instability problems.

The Mode Shape for the $\lambda=-0.1058$ mode was determined using the eigenvalue program and is depicted in Figure 6 . The critical eigenvalue $\lambda=-\mathbf{0 . 1 0 5 8}$ is a global voltage collapse mode of the upper part of the power system, involving areas $A, A l$ and $C$. This mode has a maximum participation in a bus centered in area $A l$, and presents a smooth decay for systems $A$ and $C$.

\section{Table 2: Optimized Case Load-Flow Summary}

\begin{tabular}{|c|c||c|}
\cline { 2 - 3 } \multicolumn{1}{c|}{} & MW & MVAr \\
\hline Generation & $\mathbf{5 7 , 4 7 5 . 2 5}$ & $\mathbf{1 5 , 5 2 5 . 0 0}$ \\
\hline Load & $\mathbf{5 6 , 7 2 7 . 4 0}$ & $\mathbf{1 5 , 1 9 1 . 7 0}$ \\
\hline Losses & $\mathbf{6 9 7 . 9 3}$ & $2,279.58$ \\
\hline
\end{tabular}

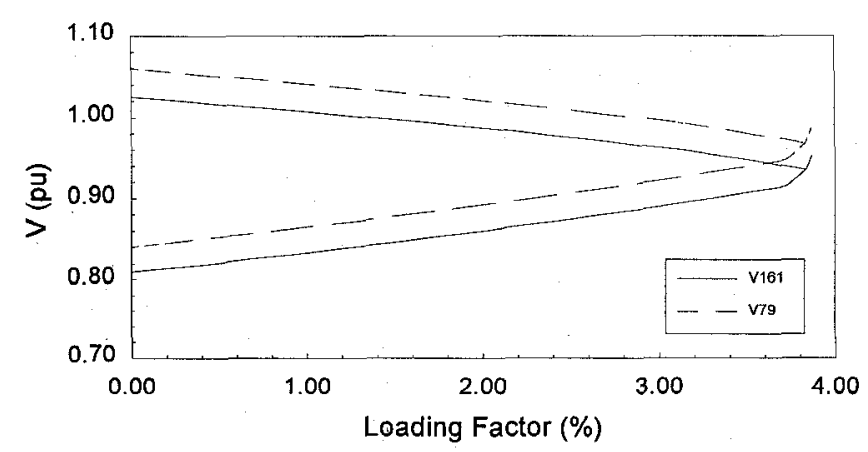

Figure 4: Point of Collapse Analysis for the Optimized Case 


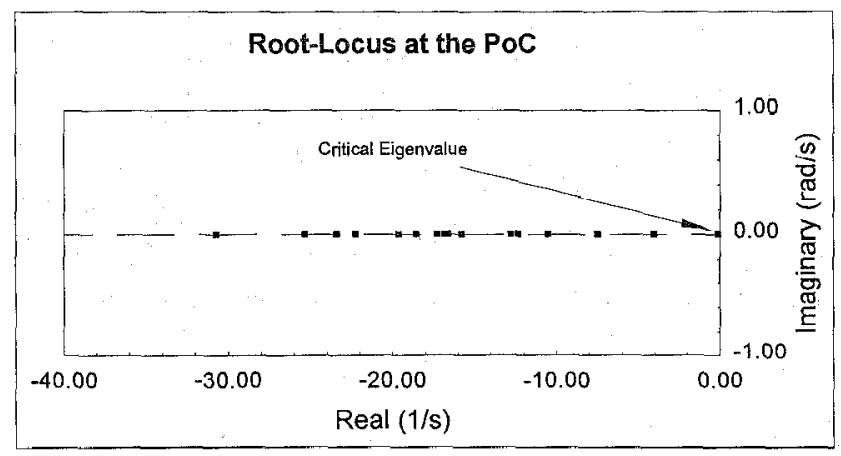

Figure 5: Critical Eigenvalue Associated to the PoC Point

The residues $\Delta V_{b} / \Delta B_{\text {shunt }}$ for the $\lambda=-0.1058$ mode were evaluated using the eigenvalue program, where $V_{b}$ is the bus voltage and $\mathrm{B}_{\text {shunt }}$ is the susceptance of a shunt reactive device. The dynamic approach indicated three buses centered in area $A I$ as the candidate buses for voltage support. It is important to note that although the eigenvalue analysis indicates the candidate buses for voltage support, it is helpless regarding the minimum amount of reactive support to solve the voltage collapse problem. At this point the OPF program is used for determining the minimum amount of reactive support for this specific situation. The candidate buses were used as an input by the OPF program and an optimized solution for the reactive power compensation at these buses was obtained. It was also observed that a near optimal solution could be obtained by allocating a capacitive shunt device at only one of the candidate buses, with a total rating of 1250 MVAr, an unacceptably large value.

The new eigenvalues of the system, after the inclusion of $1250 \mathrm{MVAr}$ of shunt compensation at the selected bus, were evaluated for an increase of load of $3.87 \%$, equal to the previous PoC, and are shown in Figure 7. The critical eigenvalue $\lambda=-0.1058$ which was associated to the voltage collapse problem in the network no longer exists. Therefore, after the proposed shunt reactive power compensation the system became voltage stable for the same increase of $3.87 \%$ of load. The new $\mathrm{PoC}$ in this case is $9.77 \%$ and the associated $V \times P$ curve is shown in Figure 8.

An eigenvalue analysis revealed that there is a new critical eigenvalue $\lambda=-0.145$ associated to the new PoC point. The mode shape analysis for this critical mode shows that the system now experiences a local voltage collapse situation in area $C_{C}$, as depicted in Figure 9.

The residues $\Delta \mathrm{V}_{\mathrm{b}} / \Delta \mathrm{B}_{\text {shunt }}$ for the new critical mode $\lambda=-\mathbf{0 . 1 4 5}$ were calculated and indicated two buses located in Area $C$ as the candidate buses for voltage support, in this local

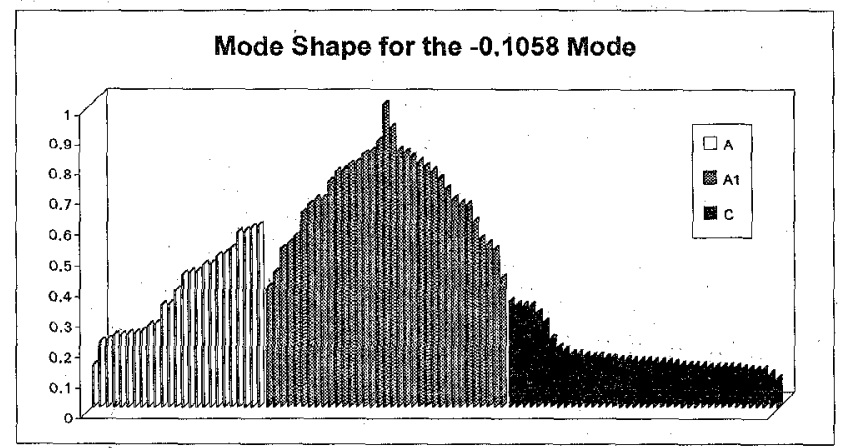

Figure 6: Mode Shape Associated to the Critical Eigenvalue

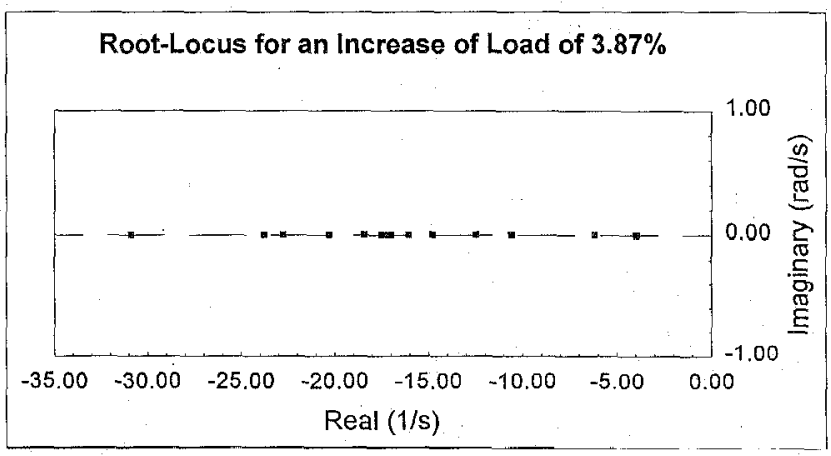

Figure 7: Eigenvalues for the Shunt Compensated Case

voltage collapse case. This information was feedback to the OPF program and a shunt device of $820 \mathrm{MVAr}$ was installed at the commutation busbar of the inverter station of DC Link \#1. Also, a $100 \mathrm{MVAr}$ shunt device was allocated at the electrical center of area $C$. Therefore, the system has now three new shunt compensation devices rated 1250 MVAr at area $A I$ and $820 \mathrm{MVAr}$ and $100 \mathrm{MVAr}$ at area $C$. The new PoC of $13.4 \%$ for the system is depicted in Figure 10.

The combined use of the continuation power flow, the eigenvalue and the optimal power flow programs increased the original PoC of the system from $2.05 \%$ to $13.4 \%$. However, notice that this increase in the overall loadability is a result of the high level of shunt compensation at buses in Area Al and Area $C$, respectively of 1250 and $820 \mathrm{MVAr}$. These are high ratings and therefore, the OPF program was used again for allocating the minimum amount of reactive power at the candidate buses with a different objective function. The design target in this case was to maintain the system voltage between specific limits, in the case of outage of important $500 \mathrm{kV}$ trunks. The final proposition for SVCs allocation is next presented:

- SVC \#1: $-100,+100$ MVAr at Area C

- SVC \#2: $-100,+300 \mathrm{MVAr}$ at Inverter \#1 Busbar

- SVC \#3: $-100,+300$ MVAr at Area AI

The final PoC of the system is $6.7 \%$ and the associated $V \times P$ curve is shown in Figure 11 .

The allocation of series devices was done using the eigenvalue program. The residues of the system were calculated in order to find the lines that maximize the relation between the deviation on the active power and the series impedance. This guarantees that in emergency situations these lines will offer the largest increase in the transient synchronizing torque as a function of the series impedance variation.

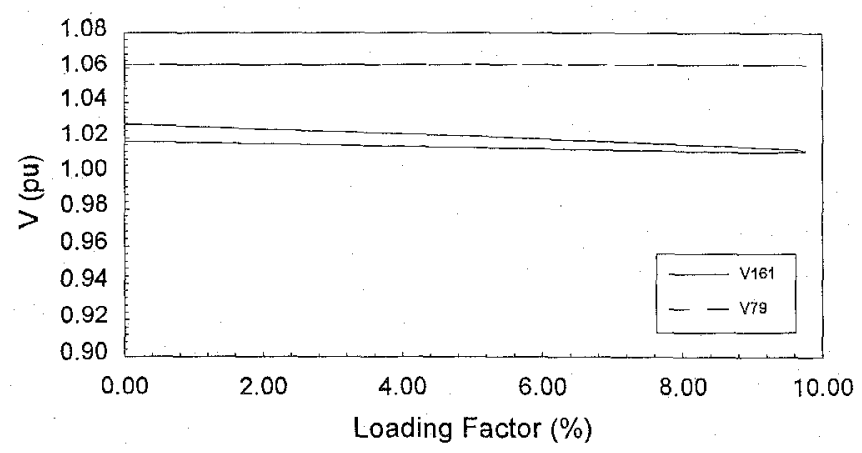

Figure 8: New Point of Collapse for the Shunt Compensated Case 


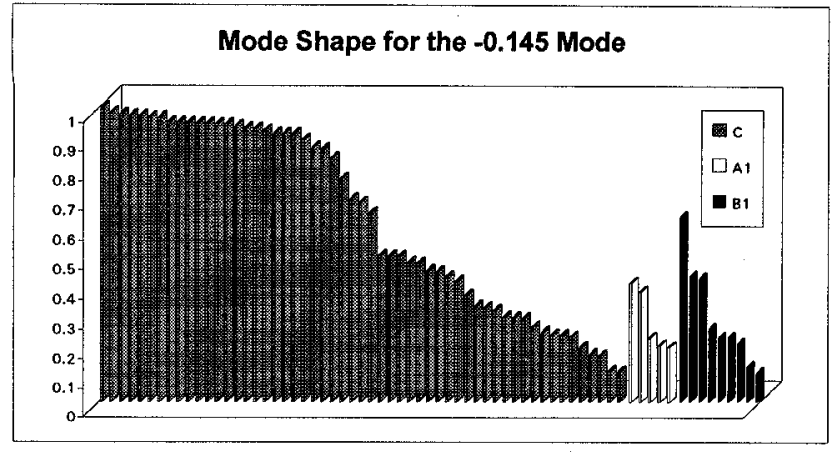

Figure 9: Mode Shape Associated to the New Critical Eigenvalue

The eigenvalue program was used for calculating the residues $\Delta \mathrm{P}_{\mathrm{ij}} / \Delta \mathrm{B}_{\mathrm{ij}}$ for the $\lambda=-\mathbf{0 . 1 0 5 8}$ critical mode, where $\mathrm{P}_{\mathrm{ij}}$ is the real (MW) power on a transmission line and $B_{i j}$ is the susceptance of a series compensation device. This dynamic approach indicated two important transmission lines as the candidate lines. These lines are parallel lines to the dc links respectively in area $B I$ and $A l$, and already had fixed series compensation. Initially, these fixed compensations were substituted by Thyristor Controlled Series Compensation - TCSC devices with the same level of maximum compensation of the previous fixed compensated lines. The final ratings of the TCSC devices were adjusted during a large disturbance dynamic performance analysis of the studied system. The basic criteria was to trip tie-lines and guarantee that the TCSC could maintain the ordered current. The following TCSC ratings were adopted:

- TCSC \#1: $\quad$ Line in Area $A 1 \Rightarrow \quad 10-90 \%$

- $\quad$ TCSC \#2: $\quad$ Line in Area B1 $\Rightarrow \quad 25-90 \%$

The dynamic stability study presented in the next section illustrates a typical situation where FACTS Controllers are coordinated to improve both transient voltage and power stability.

\section{DYNAMIC STABILITY ANALYSIS}

The need to increase the power transfer limits of the existing ac transmission systems presents new challenges to power system planners and operators. A higher level of power transfer capability may result in a reduction of the system synchronizing and damping capabilities, as well as voltage instability problems, frequency control problems and poor fault recovery performance.

Several dynamic stability study cases were analyzed taking into consideration faults which could result in the loss of an ac tieline, since this usually is the most common source of interarea oscillation problems.

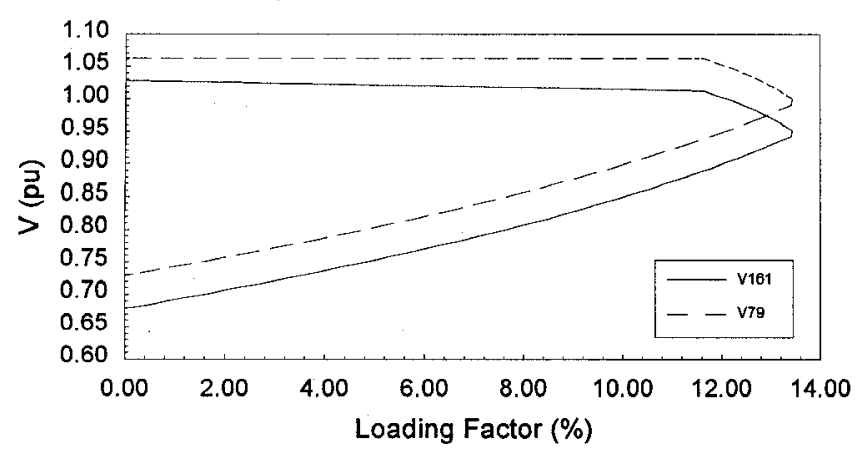

Figure 10: New Point of Collapse with Three Shunt Compensation Devices

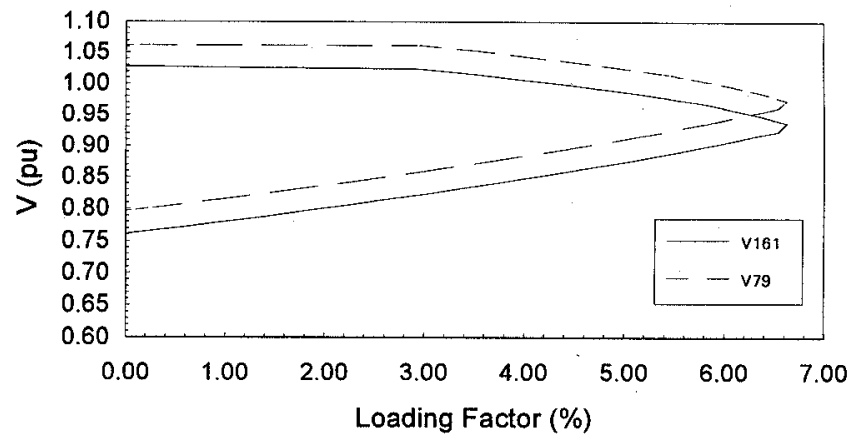

Figure 11: Final Point of Collapse with Three Static VAr Compensators

Special attention was dedicated to observe the power swings between the main Systems $A, B$ and $C$. For each one of these systems, a corresponding weighted average of their generator power angles was calculated. The weighting factors used were the rated MVA of each power plant. The relative interarea power angle swings were then obtained by the differences between the corresponding weighted average power angle of each system.

The SVC stations were operated in local voltage control while the TCSC units were operated in local current control. Both HVdc converters were set to current control at the rectifier stations, while the inverter stations were kept operating in constant minimum gamma control. The HVdc master controls were set to constant power mode in both links.

In all cases analyzed, the proposed FACTS Controllers have successfully solved voltage instability problems and have strengthened the synchronizing torque between the transmission systems. These investigations have proved the validity of the proposed methodology.

\section{COORDINATION OF FACTS CONTROLLERS TO ENHANCE POWER SYSTEM DYNAMIC PERFORMANCE}

An extremely severe case that was investigated was the blocking of a bipole (DC Link \#1) that was delivering approximately $3000 \mathrm{MW}$. A blocking signal was applied to DC Link \#1, increasing the rectifier firing angle from the steady-state value to $120^{\circ}$. This bipole experienced a power reversal to discharge the dc line and was finally blocked as shown in Figure 12. The system lost synchronism after a few seconds and, as a consequence, the ac system voltages collapsed.

Figure 13 shows the voltage collapse effect in DC Link \#2. Both the dc power and dc voltage collapses after 1.5 seconds while the dc current increases up to the maximum current limit of the Master Controller. Figure 14 shows the interarea relative angles of the system depicted in Figure 1, without considering the FACTS Controllers.

The same contingency is shown in Figure 16, but now including the FACTS Controllers. The SVCs were set to local voltage control while the TCSCs were operating coordinated by a centralized current controller depicted in Figure 15. In fact, the TCSC devices were regulating a combination of the ac power injected into its own terminal plus the ac power at the rectifier station of each dc link. The interarea relative angles show that the system became stable, reaching a new steady-state condition.

Figure 17 shows the power flow on the series compensated lines. It is clear that with the controlled series compensation the ac 
power was deviated from DC Link \#1 to both TCSC circuits. The TCSC lines redirected most of the power flow after the permanent blocking of DC Link \#1.

This is a representative result showing the importance of a coordinated procedure for control design in FACTS assisted power systems. The SVCs were designed to avoid the voltage collapse problem while the TCSCs were designed to redispatch the power flow and avoid synchronization problems after a Bipolar blocking (loss of $\approx 3000 \mathrm{MW}$ ).
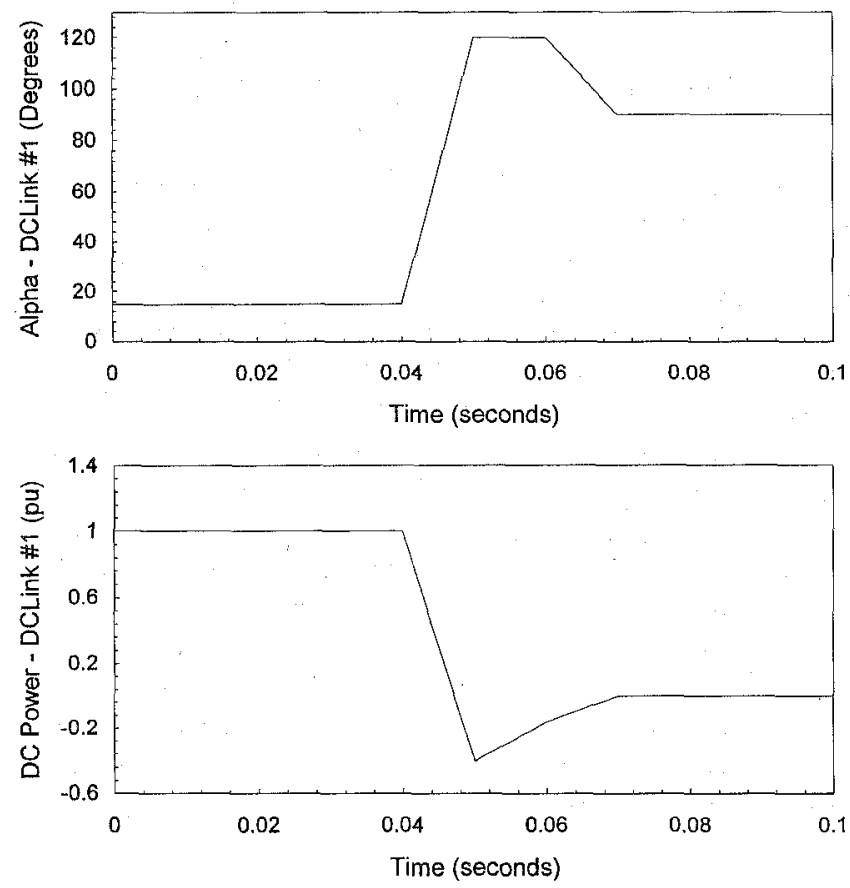

Figure 12: Bipole \#1 Blocking

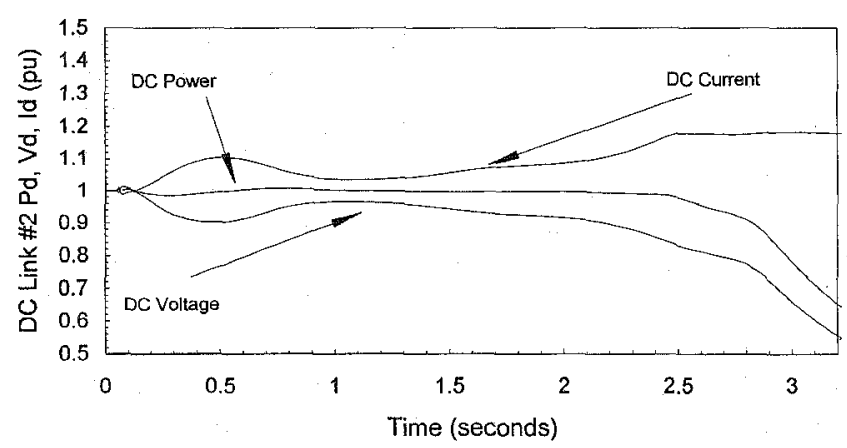

Figure 13: DC Link \#2 Voltage Collapse

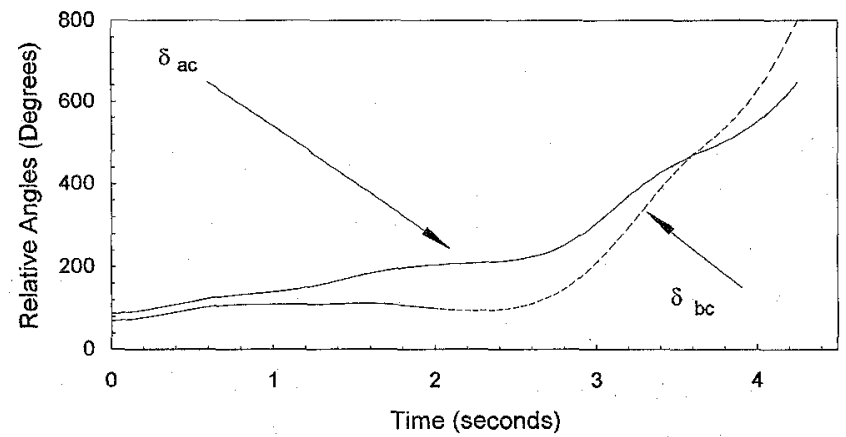

Figure 14: Interarea Relative Angles Without FACTS Controllers

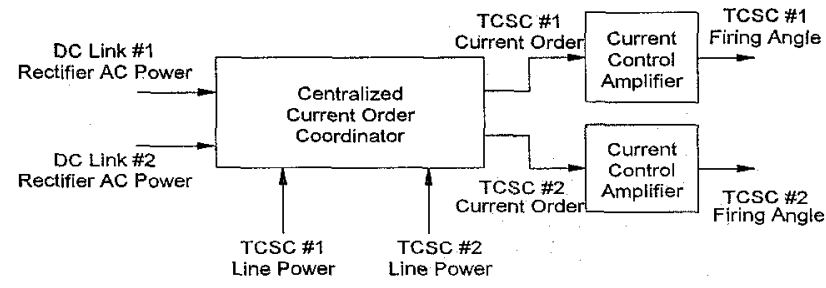

Figure 15: TCSC Current Order Coordinator

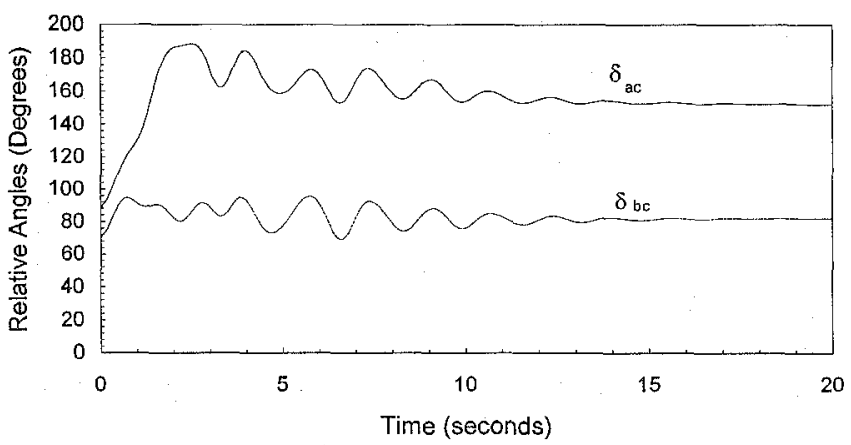

Figure 16: Interarea Relative Angles with FACTS Controllers

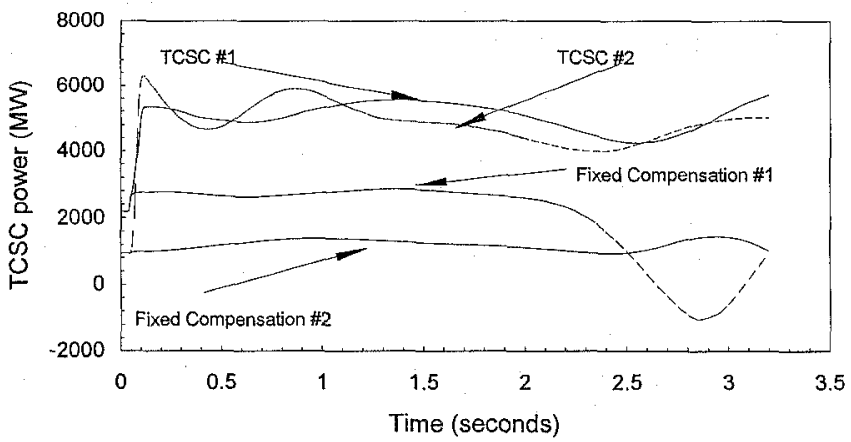

Figure 17: AC Power Flow with and without FACTS Controllers

\section{CONCLUSIONS}

A combined static/dynamic procedure for allocation of FACTS Controllers was presented. This procedure is based on the interactive use of an eigenvalue program, an optimal power flow program and the Point of Collapse methodology. Shunt devices are allocated to solve voltage collapse problems that may occur during major faults or due to a load level increase. Series devices are allocated to guarantee the maximum synchronizing torque between electrical areas during severe faults like the loss of an important tie-line.

For the network under analysis, a realistic allocation of FACTS Controllers resulted in an increase of the maximum loadability of the system from an original value of $2.05 \%$ to $6.7 \%$. Three new SVCs and two new TCSCs were proposed for the basic network. One of the SVCs was allocated at the inverter commutation busbar of DC Link \#1, which will be an interesting opportunity to analyze possible control interactions between these two different FACTS Controllers, throughout the research project [2]. 
Several transient stability cases were investigated and have proved that the allocated FACTS Controllers in fact solved voltage collapse and lack of synchronizing torque problems for the studied network. More specifically, a severe case involving the complete blocking of a bipole was investigated. It was shown that without the proposed FACTS Controllers the system became unstable due to a combined voltage collapse and lack of synchronizing torque problem.

The dynamic stability study showed that a cooperative control action between the proposed SVC and TCSC devices is an efficient solution to solve interarea stability problems. The SVCs sustained the system voltages, avoiding the voltage collapse situation, while the TCSC devices supplied the necessary synchronizing torque to guarantee the electromechanical stability of the system.

\section{REFERENCES}

[1] A. Edris, "Flexible AC Transmission System: The State of the Art", IV SEPOPE Symposium, Paper IP-17, Foz do Iguaçú, Brazil, May, 1994.

[2] L.A.S. Pilotto, W.W. Ping, A.R.D. Carvalho, A. Wey, W.F.Long, F.L. Alvarado, C.L. DeMarco, "Analysis of Control Interactions on FACTS Assisted Power Systems", EPRI Research Project 3022-33,34: First Interim Report, June, 1995.

[3] L.A.S. Pilotto, W.W. Ping, A.R. Carvalho, S. Prado, A. Wey, W.F. Long, A. Edris, "First Results on the Analysis of Control Interactions on FACTS Assisted Power Systems", Flexible AC Transmission Systems (FACTS 3): The Future in High-Voltage Transmission, Baltimore, October, 1994.

[4] EPRI, "DC Multi-Infeed Study", EPRI Final Report TR-104586, December, 1994.

[5] C.A.Cañizares, F.L. Alvarado, C.L. DeMarco, I. Dobson, W.F. Long, "Point of Collapse Methods Applied to AC/DC Power Systems", Transactions on Power Systems, Vol. 7, No. 2, pp. 673-683, May, 1992.

[6] H.J.C.P. Pinto, N. Martins, X. Vieira, A. Bianco, P. Gomes, M.G. Santos, "Modal Analysis for Voltage Stability: Applications at Base Case and Point of Collapse", Bulk Power System Voltage Phenomena III: Voltage Stability Security and Control, Davos, Switzerland, pp. 215-228, August, 1994.

\section{ACKNOWLEDGMENTS}

The authors would like to thank Dr. Martins, Mr. Bianco and Mrs. Prado, all from CEPEL, for many helpful discussions and valuable suggestions during the preparation of this paper.

\section{BIOGRAPHIES}

Luiz A.S. Pilotto (M'87) was born in Rio de Janeiro, Brazil, on June 20, 1959. He received the B.Sc., M.Sc. and D.Sc. degrees in electrical engineering, in 1981, 1983 and 1994, respectively, from the Federal University of Rio de Janeiro. Since 1983 he has been working at CEPEL, the Brazilian Electrical Energy Research Center, where he is currently a Project Manager at the Power Systems Area. Dr. Pilotto's research interests are in the analysis of HVdc transmission systems, FACTS devices and Power Electronic controllers.
Wo W. Ping was born in Wenchou, China, on June 03, 1957. He received the B.Sc. in 1979 and the M.Sc. in 1985, both in electrical engineering, from the Federal University of Rio de Janeiro. He has been working at CEPEL since 1978 on software development. $\mathrm{He}$ is currently involved in modeling FACTS devices for power systems analysis programs, along with dynamic studies on systems involving FACTS devices and HVdc systems.

Antônio R. Carvalho was born in Rio de Janeiro, Brazil, on September 16, 1959. He graduated in electrical engineering from the Federal University of Rio de Janeiro in 1981 and received his M.Sc. from the same University in 1987. Mr. Carvalho has been working at CEPEL, the Brazilian Electrical Energy Research Center, since 1986, where his currently a Project Manager at the Power System Area. His fields of interest are HVdc transmission, FACTS devices and Electromagnetic Transients studies.

Acácio Wey (M'94) received his B.Sc. degree from Mackenzie University in São Paulo, in 1971. He joined Promon, a Brazilian consulting company, in 1978 as senior engineer. During this period he has conducted many power system engineering studies for ac and dc systems to both national and international clients. From 1979 to 1984 he had actively participated in all phases of the Itaipu Project, from engineering studies till commissioning.

Willis F. Long (M'69, F'89) received his B.Sc. and M.Sc. in Engr. Physics and E.E. from the University of Toledo, and the Ph.D. in E.E. from the University of Wisconsin - Madison in 1970. He was a technical staff member at Hughes Research Labs. and Director of ASEA Power Systems Center, New Berlin, WI. Since 1973 he has been on faculty of the University of Wisconsin - Madison. Dr. Long's research interests are in the analysis and simulation of HVdc transmission systems.

Fernando L. Alvarado (F'93) obtained a Ph.D. from the University of Michigan. He is currently a Professor at the University of Wisconsin in Madison in the Department of Electrical and Computer Engineering. His main interests are in computer applications to power systems and large scale problems.

Christopher L. DeMarco (S'80, M'85) was born in Derby, Connecticut in 1958. He received his Bachelor of Science degree in Electrical Engineering from the Massachusetts Institute of Technology in June of 1980, and his Ph.D. degree in Electrical Engineering and Computer Sciences from the University of California, Berkeley in May 1985. In January 1985, he joined the faculty of the University of Wisconsin-Madison, where he is a professor in the Department of Electrical and Computer Engineering.

Abdel-Aty Edris (SM'88) was born in Cairo, Egypt in 1945. He received his B.Sc. from Cairo University in 1967, the MS. from Ain-Shams University, Egypt in 1973 and the Ph.D. from Chalmers University of Technology, Sweden in 1979. Dr. Edris joined ASEA (now ABB) in Vasteras, Sweden in 1981. From 1982 to 1986 he was involved in power systems analysis of HVdc and reactive power compensation projects. From 1986 to 1990 he worked with development projects introducing new concepts improving power systems performance. From 1990 to 1992 he was with Transmission and Relaying Center of ABB's Advanced Systems Technology in Pittsburgh. In 1992, Dr. Edris joined Electric Power Research Institute (EPRI) as a Manager of Flexible AC Transmission Systems (FACTS). Dr. Edris is a member of a number of IEEE and CIGRÉ WGs. 


\section{Discussion}

Claudio A. Cañizares (University of Waterloo): The authors should be commended for a very interesting paper discussing the issue of location and design of SVCs and TCSCs to improve the static and dynamic performance of a power system. This discusser is particularly interested in the techniques used in the paper to design and model the proposed SVCs, so that the system loadability is increased. Thus, the authors' response to the following comments and question would be greatly appreciated:

1. A similar eigenvalue methodology than the one used in the paper was used by this discusser and his co-author in [A] to determine the "optimal" location of SVCs and TCSCs that maximize system loadability, with similar results to the ones reported here. In that paper, steady state models for SVCs and TCSCs were also proposed, and a technique was suggested to determine the rating of these devices, their limits and controls, so that maximum loading conditions were improved.

The authors mention that an OPF was used to determine and "optimal" value of shunt compensation for the sample system. However, it is in not clear to this discusser what objective function was used in the OPF to determine these values, and what the meaning of "near optimal solution" is in that context. Was the OPF used to maximize the maximum system loading? If that is the case, how was that accomplished? Also, what was the model of the SVC used in the Point of Collapse program to obtain Fig. 11?

2. A similar system to the one shown in Fig. 1 in the paper was used by this discusser to obtain Figure A, which shows how the maximum loadability of the system changes as the MVAr rating of a SVC located at the system "critical" bus is changed. Notice the sharp variation in the maximum load, triggered by generator Q limits and SVC limits. In this case, the maximum loading reaches a plateau were it changes very little with respect to changes in the MVAr rating of the SVC.

An interesting problem is to determine the "optimal" value of the SVC rating that maximizes the distance to collapse, and a generic technique is proposed in [B] to accomplished just that for any parameters in the system. The optimization, however, should not only be based on maximizing the

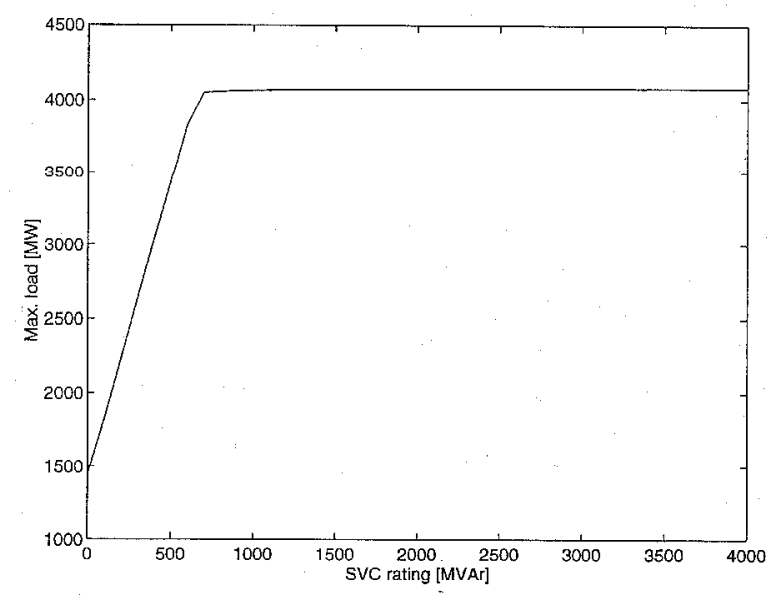

Fig. A. Maximum loading versus SVC rating in a sample system.

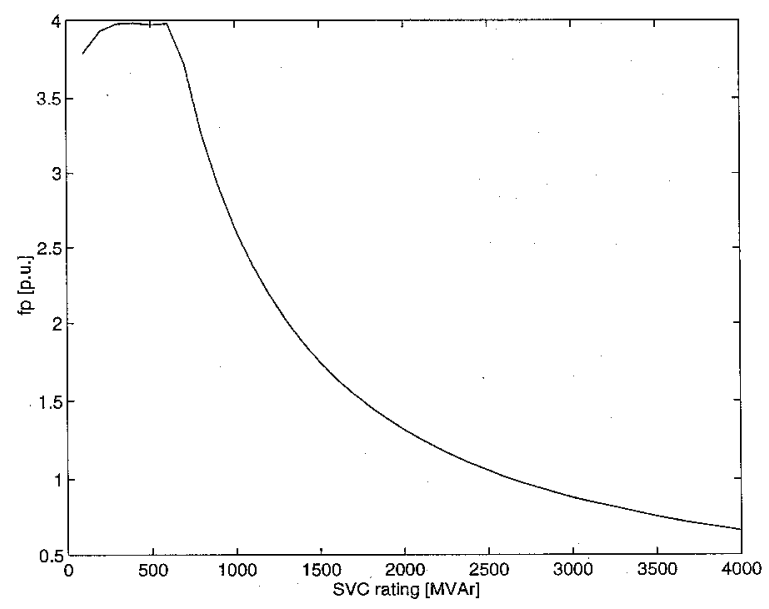

Fig. B. Optimum SVC rating in a sample system.

loading margin, but how cost effective the devices are, e.g., how the rating of the device compares to changes in the loading margin $[\mathrm{A}]$. This is depicted in Fig. $\mathrm{B}$, where the factor $f_{p}=\triangle M W_{\operatorname{margin}} / M V A r_{S V C}$ is plotted against the SVC rating for the sample system; observe that the maximum value of $f_{p}$ does not correspond to the maximum loading margin. In this case, determining the effect of the SVC rating and other system parameters in an objective function other than the loading margin may be of more value.

[A] Z. T. Faur and C. A. Cañizares, "Effects of FACTS devices on system loadability," Proc. North American Power Symposium, Bozeman, Montana, October 1995, pp. 520-524.

[B] C. A. Cañizares, "Calculating optimal system parameters to maximize the distance to saddle-node bifurcations," technical report 95-07, University of Waterloo, July 1995. Submitted for publication in the IEEE Trans. Circuits and Systems-I.

Manuscript received February 20, 1996.

L.A.S. Pilotto, W.F. Long and A. Edris: The authors wish to thank Prof. Cañizares for his interest, valuable comments and questions.

The objective function adopted during the OPF studies aimed at minimizing reactive expansion costs $[\mathrm{A}]$. A voltage range was specified for system operation and the minimum amount of reactive support was calculated to keep the system voltages within that band. The dynamic approach, based on residues calculation, resulted in three candidate buses to be used as an input by the OPF program. The OPF program was used for calculating the minimum necessary reactive support and a total of 1250 MVAr was distributed among the three candidate buses. However, these buses are electrically close and therefore a "near optimal solution" was obtained by concentrating all the necessary reactive support at only one bus. This bus was the one with the highest residue in the 
eigenvalue analysis. The authors made no attempt to use the OPF program to maximize the system loading.

The SVC devices were modeled as PV buses until the SVC limits were reached. At this point, the SVCs were assumed to supply constant reactive power. The authors are aware that this is an approximation to the real behavior of an SVC device since in the normal range of operation the droop present in actual equipment is not represented. Also, after reaching a limit the SVC behaves like a constant impedance rather than a constant reactive power source. The program being currently adopted by the authors to calculate $\mathrm{V} \times \mathrm{P}$ curves incorporates these enhanced models for SVC devices.
The authors concur with Prof. Cañizares that the optimization process should not be based exclusively on loading margin maximization but has to take into account how the ratings of the devices compares to changes in loading margins.

\section{References}

[A] S. Granville, M.C.A. Lima, "Application of Decomposition Techniques to VAr Planning: Methodological \& Computational Aspects", IEEE PES Winter Meeting 1994, Paper 94 WM 225-3 PWRS, January, 1994.

Manuscript received April 1, 1996. 